\title{
Catalytic oxidation of nitrobenzene in a fixed bed reactor
}

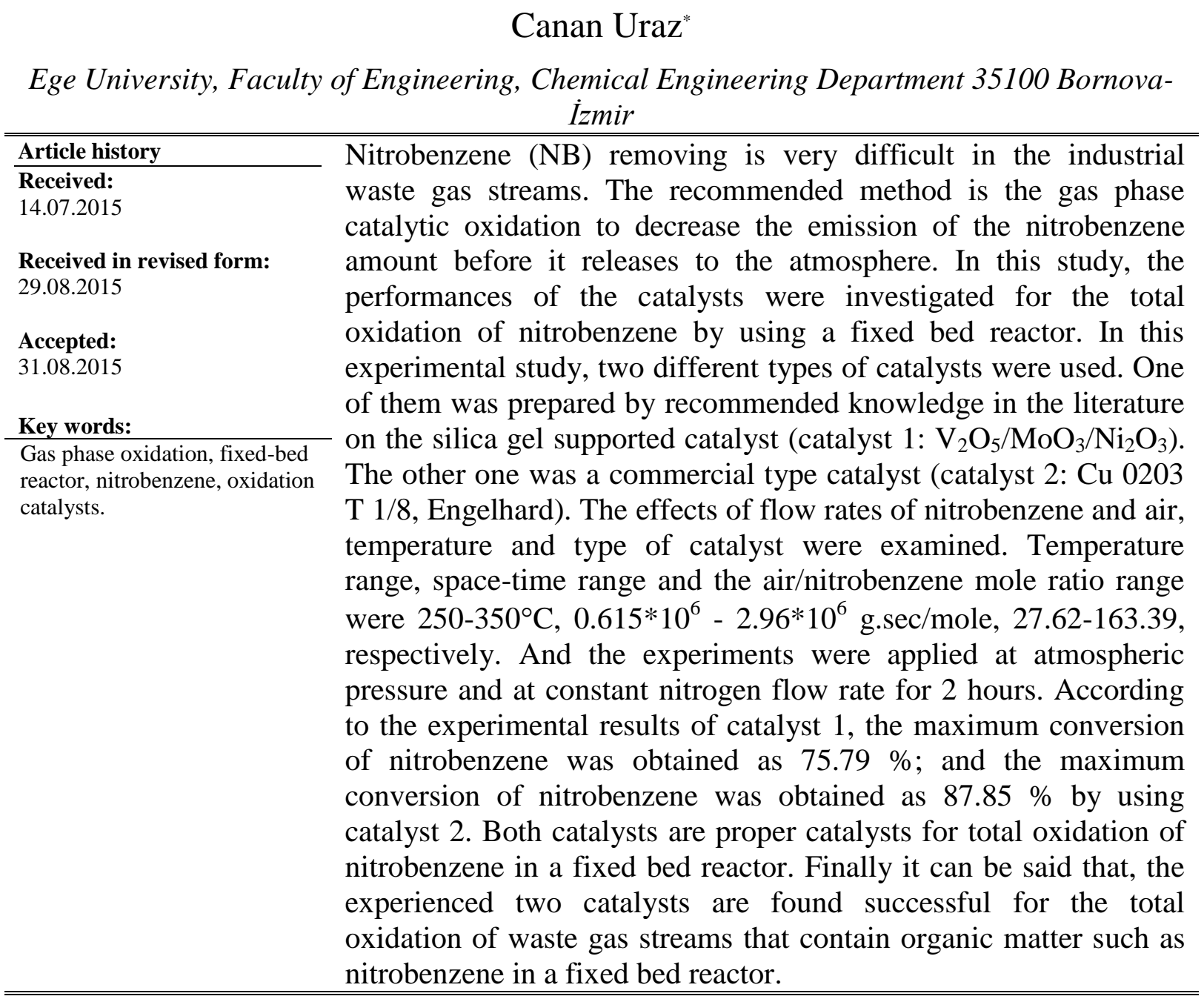

* Correspondence: Tel No:+90(232)3111486; Fax No: +90(232)3887776; canan.uraz@ege.edu.tr 


\section{Introduction}

Waste removal problems are very important. So for this purpose a lot of techniques are developed to eliminate the hazardous chemicals from domestic and industrial wastes by using various types of catalysts [1, 2, and 3]. Recently, a lot of studies about gas phase catalytic oxidation process for the abatement of hazardous chemicals; can be seen in the literature. Yalcuk is studied wastewater treatment for removal of phenol [4]. The other study is about methane oxidation in soil [5].

Nitrobenzene is used for the production of aniline and its derivatives (methyl diphenyl diisocyanate). It is also used in the manufacture of rubber chemicals, pesticides, dyes, and pharmaceuticals, in shoe and floor polishes, leather dressings and paint solvents [6].

Human body can be affected from high nitrobenzene vapor and it may cause skin cancer [7]. Some emission regulations are used for the usage limit of the nitrobenzene to health effect in many countries. A lot of methods are developed for the elimination of nitrobenzene. But some of them are not useful for low concentrations of nitrobenzene. The most suitable techniques are thermal oxidation, catalytic oxidation, and carbon adsorption [8-11].

In this study waste gas stream that contains nitrobenzene were treated in a fixed bed reactor by using oxidation catalysts. The oxidation catalyst prepared in laboratory and commercial type catalysts were used for total oxidation of nitrobenzene in a fixed bed reactor to test the effects of the parameters: temperature, space time and nitrobenzene / air mole ratio.

\section{Material and Methods}

\section{Catalyst Preparation}

In this study, two catalysts were used to test the performance for total oxidation of nitrobenzene in a fixed bed reactor. One of them was obtained by recommended knowledge in the literature [12] and the other catalyst was a commercial catalyst. Composition of catalyst 1 and catalyst 2 are given in Table 1 and Table 2.

Table 1. Chemical Composition of catalyst 1.

\begin{tabular}{|l|c|c|}
\hline \multicolumn{2}{|c|}{$\begin{array}{c}\text { Type of the carrier and \% by } \\
\text { weight }\end{array}$} & Silica Gel (72) \\
\hline $\begin{array}{l}\text { Compositions } \\
\text { of active } \\
\text { ingredient, } \\
\text { wt\% }\end{array}$ & $\mathbf{V}_{2} \mathbf{O}_{\mathbf{5}}$ & 53.6 \\
\cline { 2 - 3 } & $\mathrm{MoO}_{\mathbf{3}}$ & 35.7 \\
\cline { 2 - 3 } & $\mathrm{Ni}_{\mathbf{2}} \mathbf{O}_{\mathbf{3}}$ & 10.7 \\
\hline
\end{tabular}

Table 2. Typical physical properties of catalyst 2.

\begin{tabular}{|l|c|}
\hline \multicolumn{2}{|c|}{ Physical Properties } \\
\hline Particle Shape & Cylindrical \\
\hline Total pore Volume & $0.10 \mathrm{~cm}^{3} / \mathrm{g}$ \\
\hline Apparent Bulk Density & $2.0 \mathrm{~g} / \mathrm{cm}^{3}$ \\
\hline Average Crush Strength & $9.1 \mathrm{kgs}$ \\
\hline Surface Area & $10 \mathrm{~m}^{2} / \mathrm{g}$ \\
\hline
\end{tabular}

\section{Catalyst 1}

First catalyst was prepared in the following steps:

- Silica-gel was mixed with $57.6 \mathrm{ml}$ of $\mathrm{H}_{2} \mathrm{O}$, $72 \mathrm{ml}$ of $\mathrm{HCl}, 14.4 \mathrm{ml}$ of $\mathrm{HNO}_{3}$ in a porcelain basin.

- $\mathrm{V}_{2} \mathrm{O}_{5}$ was mixed with water at around $80^{\circ} \mathrm{C}$ by heating on a hot plate.

- Oxalic acid in powder form was added to the mixture in specified amount.

- $\mathrm{V}_{2} \mathrm{O}_{5}$ was completely dissolved until it was given a deep blue color to the solution by stirring. This solution was known as Solution A.

- Solution B was prepared by dissolving ammonium molybdate in water. And for 
Solution C, nickel nitrate was dissolved in water.

- Solutions A, B and C were mixed and 36 $\mathrm{ml}$ mixture of these solutions was replaced in a sand bath for $10-12$ hours at $100^{\circ} \mathrm{C}$.

- Then acid was decanted off and the gel treated once more with $36 \mathrm{ml}$ of the mixed acid. And then it was heated and mixed frequently for $2 \mathrm{~h}$.

- After the acid was descended from the solution, water was drained off.

- The gel was dried in an oven and it was replaced on silica trays and left in a furnace.

- The temperature of the furnace was increased gradually to $700^{\circ} \mathrm{C}$ in 5 hours and kept at this temperature for 2 hours.

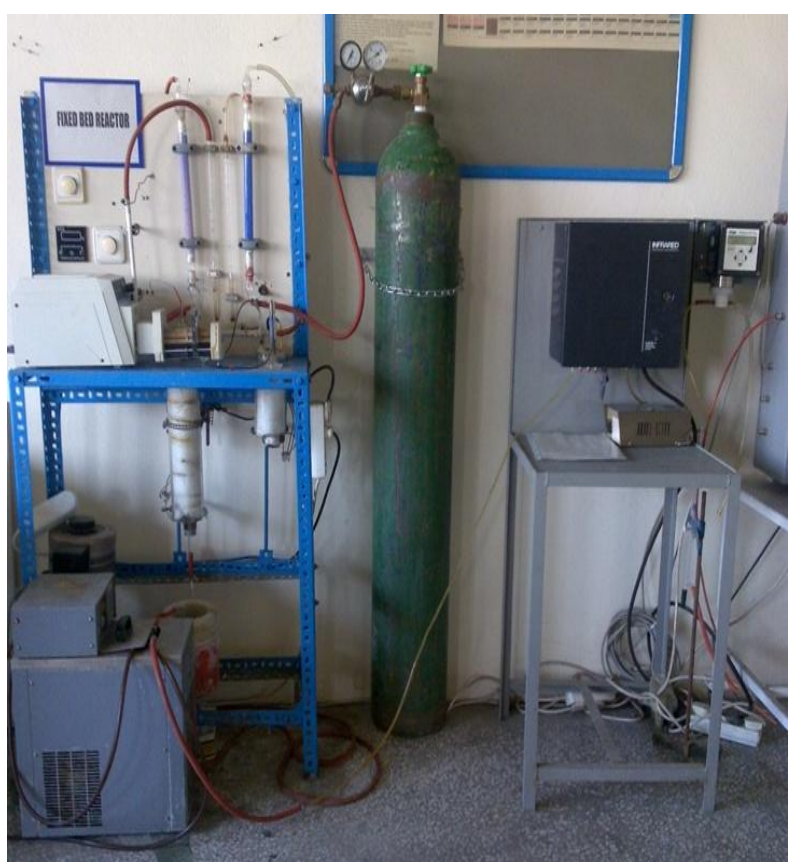

Figure 1. Experimental Set up.

The experimental set up consists of the following parts:

Air Stream: As a source of oxygen, air stream is used. Air is obtained from the atmosphere by a pump and then the air is sent to a column filled with silica gel and glass

\section{Catalyst 2}

Catalyst 2 was a commercial catalyst name of $\mathrm{Cu} 0203 \mathrm{~T} 1 / 8$ mainly consists of Copper 60 wt \% and Chromium $10 \%$ (Engelhard Copper - Chromite Catalyst). The chemical composition and typical physical properties of catalyst 2 is given in Table 2 .

\section{Experimental Set-Up}

The experimental set up is shown in Figure 1 and the schematic drawing of the fixed-bed reactor is given in Figure 2.

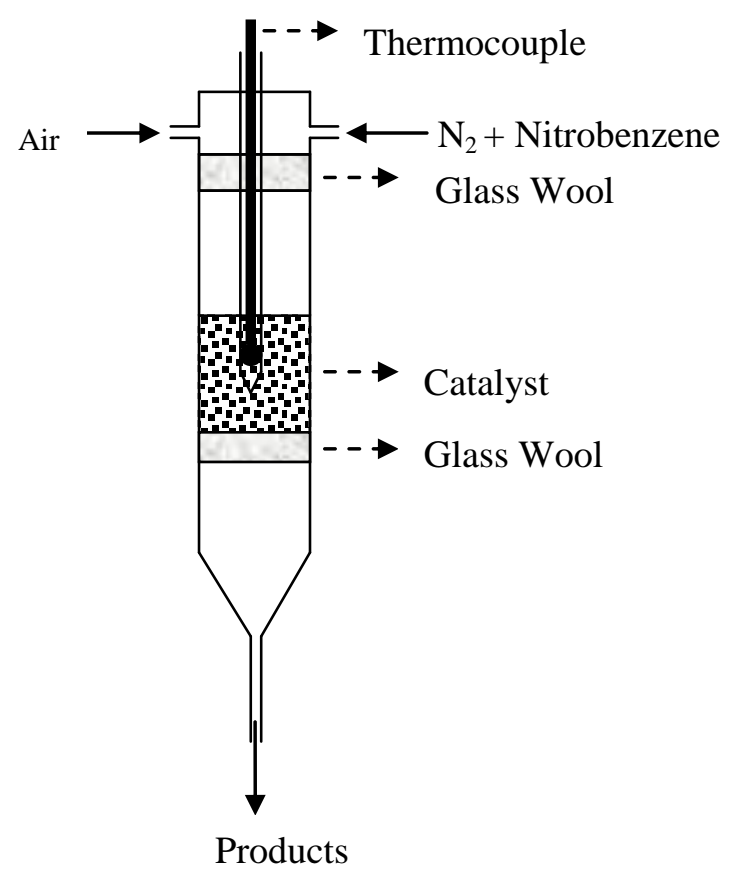

Figure 2. Fixed-Bed Reactor.

wool to absorb water and to clean impurities such as dust. Air stream is adjusted by using a flow meter is used to with a range of 1$10 \mathrm{ml} / \mathrm{s}$.

Nitrogen Stream: Nitrobenzene is carried to the reactor by nitrogen gas. The nitrogen is 
sent to a column filled with silica gel. And there is glass wool in this column to collect dust and $\mathrm{CO}_{2}$. Required flow is achieved by a sensible valve on the flow meter $(0.1-1 \mathrm{ml} / \mathrm{s})$.

Nitrobenzene Stream: Volume of nitrobenzene is recorded and is fed to the fixed bed reactor with a Cole Palmer Masterflex, model 7519-25 Cartridge pump. The flow rate of nitrobenzene is adjusted by using Microbore tubing in this peristaltic pump. Parameters that are reaction time and the nitrobenzene level in the measuring cylinder are recorded.

Preheater: Before nitrobenzene enters the reactor, it is electrically heated to 150 to $200^{\circ} \mathrm{C}$. In this section nitrobenzene is vaporized so this section behaves for benzene as a vaporizer. The nitrogen stream is also directed to the preheater to carry the vaporized nitrobenzene to the reactor.

Reactor: Reaction is carried out by using Pyrex glass fixed bed reactor. Reaction temperature is controlled with a temperature controller. Size of the reactor is $2 \mathrm{~cm}$ in diameter and $21 \mathrm{~cm}$ in length. Two different types of catalysts are used in this study and they are placed into the catalyst bed. The temperature of the catalyst bed is controlled with a resistant thermometer. Granular catalyst is fixed by using glass wool under the catalyst bed. Glass packing is replaced to the top of the reactor to obtain a homogenous air flow.

Cooling and Collection: A cooled trapping system is used to cool and to collect the gas mixture at the bottom part of the reactor. The gas mixture contains the products and reactants. Reaction products and the other gases that are exits from the reactor without any reaction, a trapping system is used. These traps are like a "Y" shape tube and two of them are arranged in series and connected to the reactor exit. As a cooling medium, an ice salt mixture and alcohol water mixture cooled by refrigerant is used. During the experiments percentages amount of $\mathrm{CO}_{2}$ and the flow rate of the exit gas are recorded.

\section{Experimental Procedure}

Experimental procedure is given in the following steps:

$\checkmark$ Initially $2 \mathrm{~g}$. of pelletized catalyst is fed to the reactor and the reactor is controlled for leakage. Then the reactor is heated at $300^{\circ} \mathrm{C}$ in air stream for 1 hour.

$\checkmark$ Fixed bed reactor and preheater are heated to the required temperatures.

$\checkmark$ Cooling system is prepared.

$\checkmark$ Liquid level of nitrobenzene and time are recorded. When temperature of the reactor reaches to the desired value, nitrobenzene is sent to preheater and then reactor.

$\checkmark$ Air stream is adjusted with a flow meter. And it is sent to preheater first and then reactor.

$\checkmark$ The percentages amount of $\mathrm{CO}_{2}$ and flow rate of exit gas is measured for specified time intervals. The gas which is uncondensed is sent to atmosphere.

After 2 hours the experiment is ended, the pump, preheater and reactor are switched off. The air stream is closed.

The product mixture is analyzed by using Hewlett Packard 5890 Series II Gas Chromatograph with flame ionization detector and HP integrator.

\section{Results and Discussion}

Catalyst performance testing for total oxidation of nitrobenzene was investigated in a fixed bed reactor in this study. During the experiment some parameters were investigated: nitrobenzene and air flow rates, effect of temperature, and catalyst type on the reaction.

The consumption of nitrobenzene was calculated assuming the following reaction carried out in the reactor.

$$
\begin{array}{r}
2 \mathrm{C}_{6} \mathrm{H}_{5} \mathrm{NO}_{2}(g)+\frac{25}{2} \mathrm{O}_{2}(g) \rightarrow \\
12 \mathrm{CO}_{2}(g)+\mathrm{N}_{2}(g)+5 \mathrm{H}_{2} \mathrm{O}(\mathrm{g})
\end{array}
$$

The product mixture was analyzed at GC in noncondensable gas stream. By the help of gas chromatograph analyze and $\mathrm{CO}_{2} \%$

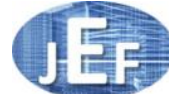


measurements during the experiments; consumptions were calculated for the reaction of nitrobenzene.

\section{Catalyst 1:}

Some of the results obtained were plotted in Figure 3. This graph was plotted for the experiments carried out at different flow rates of nitrobenzene and at three different temperatures at constant air/nitrobenzene mole ratio and constant temperatures. It can be followed from Figure 3 that, conversion of nitrobenzene decreased with increasing nitrobenzene flow rates. According to this result, it can be explained that the reaction tends to the total oxidation when the flow rate of nitrobenzene increases.

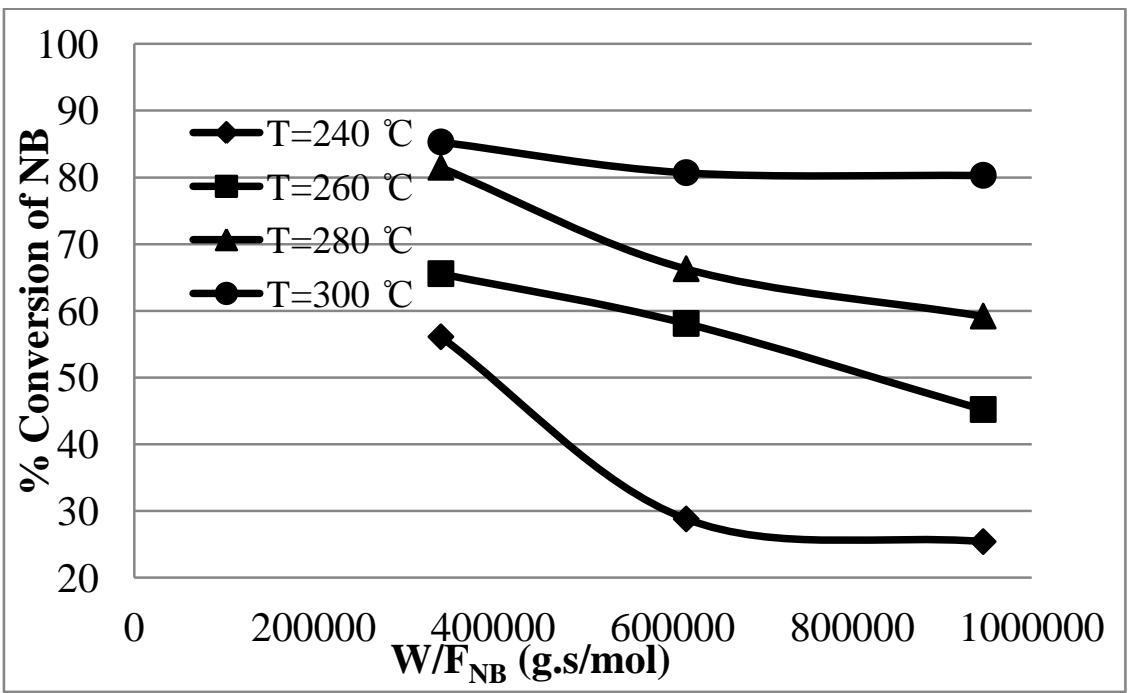

Figure 3- Space time vs. Nitrobenzene consumption at constant air/nitrobenzene mol ratio (78.104) and constant temperatures for catalyst 1.

Another graph was drawn to show the effect flow rate). Conversion of nitrobenzene of air flow rate on the oxidation of increases with increasing air flow rate nitrobenzene $\left(300^{\circ} \mathrm{C}\right.$ and $0.013 \mathrm{ml} / \mathrm{min} \mathrm{NB}$ (Figure 4).

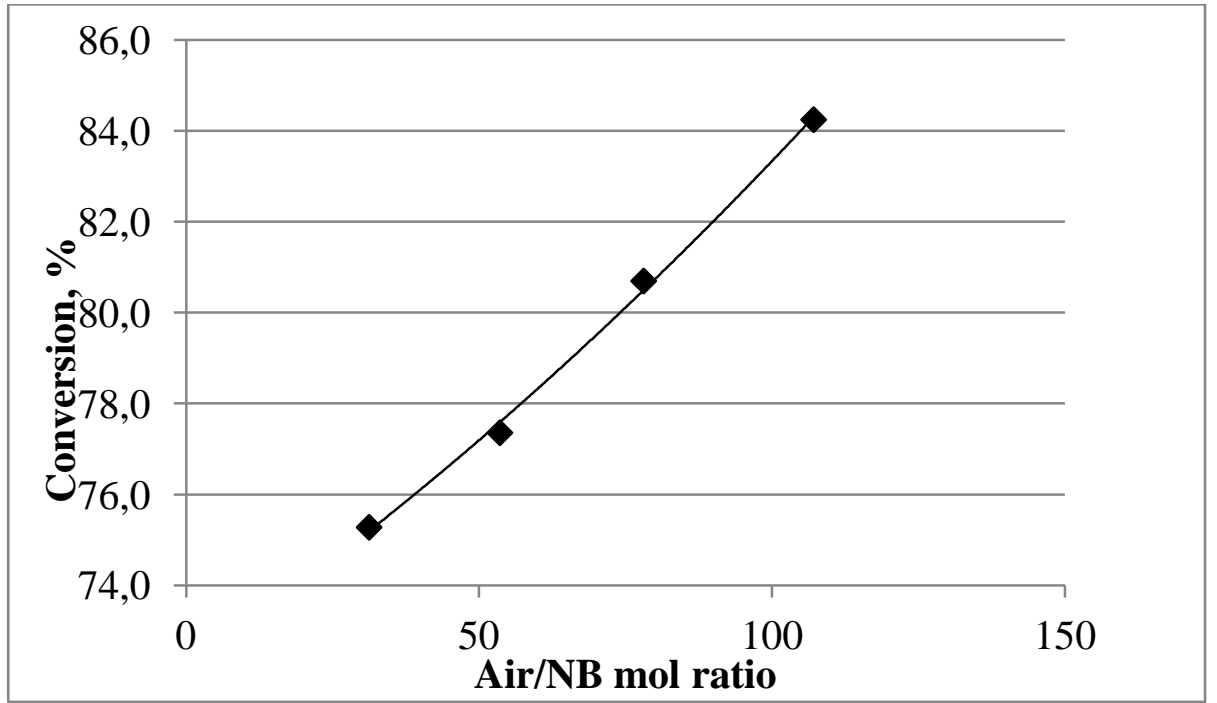

Figure 4- Air/nitrobenzene mole ratio vs. Nitrobenzene consumption at constant space time $\left(\mathrm{W} / \mathrm{FA}_{0}=9.46^{*} 10^{5} \mathrm{~g} \cdot \mathrm{sec} / \mathrm{mol}\right)$ and constant temperature $\left(300^{\circ} \mathrm{C}\right)$. 
However the experiments were carried out with fresh catalyst, it was decided to investigate the activity of the catalyst 1 . So, the experienced and the fresh catalyst were analysed by FTIR (Perkin Elmer Spectrum 100). Figure 5 shows the results of FTIR spectroscopy of experienced and fresh catalysts. In this figure, at $798 \mathrm{~cm}^{-1}, 967.26$ $\mathrm{cm}^{-1}$ and $1063 \mathrm{~cm}^{-1}$ wave numbers, the same peaks were detected. But $1300 \mathrm{~cm}^{-1}$ and 1500 $\mathrm{cm}^{-1}$ there are peaks according to $\mathrm{C}=\mathrm{O}$ (carbonyl) stretching bond in the experienced catalyst. So, it can be said that fresh catalyst should be used for this reaction or experienced catalyst should be activated for each experiment according to the recommended activation procedure.

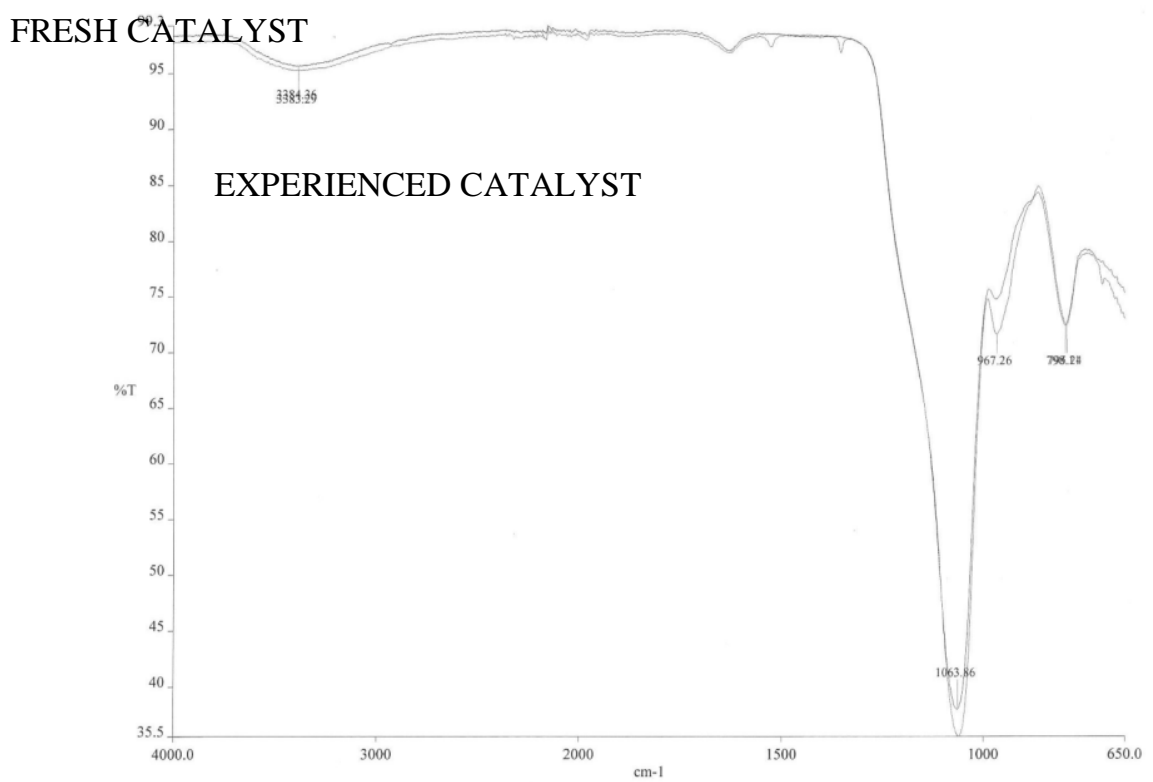

Figure 5. FTIR Spectroscopy of fresh and experienced catalysts 1.

\section{Catalyst 2}

$300^{\circ} \mathrm{C}$ temperatures. But again the same

Another graph was drawn to investigate the influence of the space time on nitrobenzene consumption (Figure 6). behavior was obtained by using catalyst 2 . When space time increased the conversion of Experiments were carried out at 260, 280,

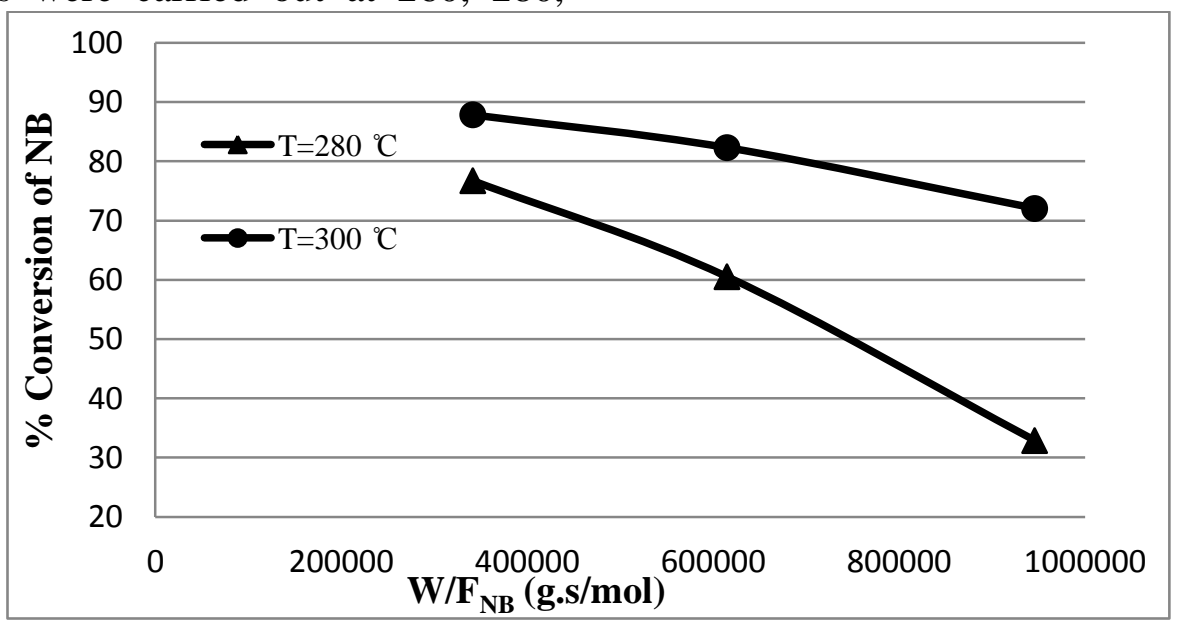

Figure 6- Space time vs. Nitrobenzene consumption at constant air/nitrobenzene mol ratio (53.56) and constant temperatures for catalyst 2. 
Lastly the air/nitrobenzene mole ratio versus nitrobenzene consumption graph was plotted. Figure 7 was obtained at $\mathrm{W} / \mathrm{F}_{\mathrm{A} 0}=10.88 * 10^{5}$ g.sec/mole and constant temperature $\left(300^{\circ} \mathrm{C}\right)$ for catalyst 2. From Figure 7 , it can be followed that, when conversion of nitrobenzene increased, air flow rate is also increased. If the comparison was made with catalyst 1, the same behavior was also obtained in this graph.

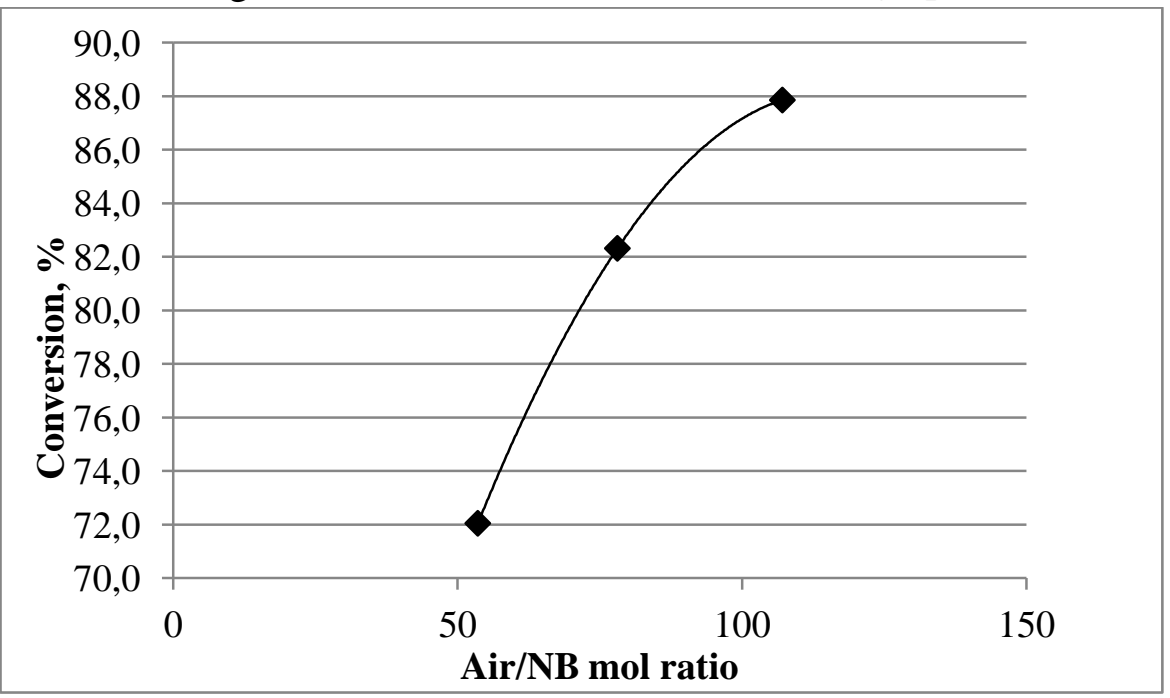

Figure 7- Air/nitrobenzene mole ratio vs. Nitrobenzene consumption at constant space time $\left(\mathrm{W} / \mathrm{FA} 0=10.88^{*} 105 \mathrm{~g} . \mathrm{sec} / \mathrm{mole}\right)$ and constant temperature $\left(300^{\circ} \mathrm{C}\right)$ for catalyst 2.

In this study waste gas streams that contain nitrobenzene should be treated in a laboratory scale fixed bed reactor by using oxidation catalysts parametrically. Experiments were carried out by using two different types of catalysts.

The maximum consumption of nitrobenzene was obtained as $85.30 \%$ by using catalyst 1 ; and the maximum consumption of nitrobenzene was obtained as $87.86 \%$ by using catalyst 2 .

It is difficult to say which catalyst is the most suitable catalyst for this study. When the two experienced catalysts are compared each other, the maximum conversion of nitrobenzene is obtained by using catalyst 2 as $87.86 \%$. Finally it can be said that, the experienced two catalysts are found successful for the total oxidation of waste gas streams that contain organic matter such as nitrobenzene.

\section{References}

1. Debellefontaine H., Chackchouk M., Foussard J.N., Tissot D., Treatment of
Organic Aqueous Wastes: Wet Air Oxidation and Wet Peroxide Oxidation. Elsevier, 1999.

2. Gennequin C., Lamallem M., Cousin R., Siffert S., Idakiev V., Tabakova T., Aboukaïs A., Bao-lian S. Total Oxidation of Volatile Organic Compounds on $\mathrm{Au} / \mathrm{Ce}-\mathrm{Ti}-\mathrm{O}$ and $\mathrm{Au} / \mathrm{Ce}-\mathrm{Ti}-\mathrm{Zr}-\mathrm{O}$ Mesoporous Catalysts. J.Mater.Sci. 2009; 44: 6654-6662.

3. Nichela D., Carlos L. and Einschlag F.G. Autocatalytic Oxidation of Nitrobenzene Using Hydrogen Peroxide and Fe (III). Elsevier, 2008.

4. Yalcuk A. Removal of Phenol from Olive Mill Wastewater in Constructed wetlands Using Different Bedding Media. Ekoloji 2011; 20, 80: 1-5.

5. Kara E.E., Özdilek H.G. The Effect of Nitrogenous Fertilizers on Methane Oxidation in Soil. Ekoloji 2010: 19, 74: $1-9$.

6. Anonymous, EPA United States Environmental Protection Agency, Nitrobenzene Fact Sheets, EPA 1995; 749-F-95-015a. 
7. Holder J. W. Nitrobenzene Carcinogenicity in Animals and Human Hazard Evaluation. Toxicol Ind Health, Toxicol Ind Health 1999; 15: 445-457.

8. Patil D.V., Somayajulu Rallapalli P.B., Dangi G.P., Tayade R.J., Somani R.S., and Bajaj H.C. MIL-53(Al): An Efficient Adsorbent for the Removal of Nitrobenzene from Aqueous Solutions. Ind.Eng.Chem.Res. 2011；50: 1051610524.

9. Mc Innes R. G. Explore new options for hazardous air pollutant control Chem. Eng. Progress 1995; 91, 11: 3648.

10. Song Y. H., Kim S. J., Choi K. and Yamamoto T. Effects of adsorption and temperature on a nonthermal plasma process for removing VOCs. J Electrostat 2002; 55: 189.

11. Karuppiah J., Sivacrandiran L., Karvembu R., and Subrahmanyam Ch. Catalytic Plasma Reactor For Abatement Of Dilute Nitrobenzene Chinese Journal of Catalysis 2011; 32: 795-799.

12. Marg R. India Patent 1299621971. 